\title{
Screening and Identification of Trichoderma Strains isolated from Natural Habitats in China with Potential Agricultural Applications
}

\author{
Ming Xue, ${ }^{1}$ Rui Wang, ${ }^{1,2}$ Chongyuan Zhang, ${ }^{1}$ Weiwei Wang, ${ }^{1,3}$ Fengtao Zhang, ${ }^{1}$ Di Chen, \\ Sen Ren, ${ }^{1}$ Zhang Manman, ${ }^{1}$ Jumei Hou, ${ }^{1}$ and Tong Liu $\mathbb{D}^{1,2}$ \\ ${ }^{1}$ Key Laboratory of Green Prevention and Control of Tropical Diseases and Pests of Ministry of Education (College of \\ Plant Protection, Hainan University), Haikou, Hainan 570228, China \\ ${ }^{2}$ Engineering Center of Agricultural Microbial Preparation Research and Development of Hainan (Hainan University), Haikou, \\ Hainan 570228, China \\ ${ }^{3}$ Key Laboratory of Genetics and Germplasm Innovation of Tropical Special Forest Trees and Ornamental Plants of Ministry of \\ Education (College of Forest, Hainan University), Haikou 570228, China
}

Correspondence should be addressed to Tong Liu; liutongamy@sina.com

Ming Xue and Rui Wang contributed equally to this work.

Received 17 June 2021; Revised 9 November 2021; Accepted 18 November 2021; Published 21 December 2021

Academic Editor: Joana Barbosa

Copyright (c) 2021 Ming Xue et al. This is an open access article distributed under the Creative Commons Attribution License, which permits unrestricted use, distribution, and reproduction in any medium, provided the original work is properly cited.

Trichoderma spp. are widely distributed in natural habitats and have been evaluated as a potential biocontrol agent (BCA) for disease control and plant growth promotion. In this study, 1308 Trichoderma strains were obtained from the plant rhizosphere soil, above-ground plants, and decaying wood from natural habitats in China. Among them, 49 Trichoderma strains showed a good inhibitory effect, especially against Botrytis cinerea, Fusarium oxysporum, and Colletotrichum gloeosporioides with inhibition rate above $85 \%$ in the dual culture test. Among these 49 strains, the 13 strains with broad-spectrum inhibitory effects also significantly promoted the seed germination of five crops (rice, cucumber, tomato, melon, and pakchoi) and root growth of four crop seedlings (watermelon, tomato, eggplant, and chili). Furthermore, these strains showed effective colonization in the rhizosphere and root of cucumber. Trichoderma strains SC012 and NX043 showed the highest chitinase and $\beta$-1,3-glucanase activity among all strains. Based on the morphological characterization and phylogenetic analysis of the nuclear ribosomal internal transcribed spacer (ITS) and translation elongation factor 1 (tef1), twelve Trichoderma strains were identified as Trichoderma asperellum and one as Trichoderma afroharzianum. This study suggests that the 13 Trichoderma strains are promising BCAs and could be developed as biofertilizers and biological pesticides for agricultural applications.

\section{Introduction}

Soil-borne diseases significantly decrease the quality and quantity of cash crops including vegetables, fruits, and officinal plants [1]. Most of the causal agents are polyphagous ubiquitous fungi, such as $F$. oxysporum causing wilt $[2,3], C$. gloeosporioides causing anthracnose $[4,5]$, and $B$. cinerea causing gray mold $[6,7]$. Currently available strategies for managing soil-borne pathogens include cultivation practices, physical control, and chemical control through resistant plants [8]. Although these approaches can reduce pathogen-caused losses, they are time-consuming and nontargeting and have poor control effects in some cases; chemical control is effective, but there are potential risks to the environment, and pathogens are prone to drug resistance [9]. Biological control is one of the best options to overcome the above-mentioned hurdles to the management of soil-borne plant pathogens and is undoubtedly more suitable for the sustainable development of modern agriculture [10]. 
Trichoderma spp. are recognized as important bioantagonists of phytopathogens in agricultural production and account for more than $60 \%$ of the registered biofungicides [11]. The biocontrol efficacy of Trichoderma is based on the activation of multiple mechanisms, including competing for nutrients and space, modifying the environmental conditions, and promoting plant growth and plant-defensive mechanisms, antibiosis, and mycoparasitism [12-15]. T. asperellum strain CCTCC-RW0014 exhibited antagonism activity to fusarium wilt disease due to its high hydrolytic activity of chitin, gelatin, carboxymethyl cellulose, and pachyman [16]. T. virens ZT05 showed a significant inhibitory effect on $R$. solani, and its mechanism of action was associated with hyperparasitism and antibiosis [17]; T. harzianum Ths97 can control F. oxysporum causing damping-off in Pinus massoniana seedlings by reducing reactive oxygen species, lowering lipid peroxidation and cell death, increasing osmolyte levels, stimulating the activities of antioxidant enzymes, and increasing soil fertility [18].

Trichoderma is one of the most diverse genera of the biocontrol fungi having above 300 reported species [19]. However, only a few of them are used in agricultural production as BCAs or biostimulating agents including T. polysporum, T. hamatum, T. virens, and T. atroviride [20-22]. Therefore, exploring the greater diversity of Trichoderma and evaluating its biocontrol effect have greater advantages in the biocontrol of plant pathogens. In addition, the success of BCAs is dependent upon the complex interactions between beneficial microbes with pathogens and plants [23]. It is a prerequisite for their effective practical application to understand how the biocontrol agents exert their protective effects [24]. In this study, we isolated 1308 Trichoderma strains various natural habitats in China and screened for their antifungal effect against a range of plant pathogenic fungi. Those strains that showed prominent antifungal activity were further tested for their plant growth and germination effect on a variety of important cash crops. The selected strains were then evaluated for root colonization ability, chitinase, and $\beta-1,3-$ glucanase activity and finally identified on morphological and molecular basis.

\section{Materials and Methods}

2.1. Strains and Media. The pathogenic fungi (B. cinerea $\mathrm{WN}-$ 2, F. oxysporum CS-1, C. gloeosporioides Penz QH-5, Sclerotium rolfsii SDF-23, F. oxysporum $f$. sp. tracheiphilum MTX-6, Botryosphaeria dothidea CTG-7, Magnaporthe oryzae DWM3, Botryodiplodia theobromae PERF-1, F. graminearum KDR1, Rhizoctonia cerealis ROD-18, Stagonosporopsis cucurbitacearum SD-3, and $R$. solani MNV-6) were isolated, identified, and stored at the Key Laboratory of Green Prevention and Control of Tropical Diseases and Pests of Hainan University for the subsequent studies.

Trichoderma selective medium (TSM) was used for the isolation of Trichoderma spp. [25]. Potato dextrose agar (PDA) medium was used to culture and preserve pathogenic fungi and Trichoderma. The $\beta$-1,3-glucanase synthetic medium (Yeast extract $30 \mathrm{~g}, \mathrm{NaNO}_{3} 3 \mathrm{~g}, \mathrm{MgSO}_{4} \cdot \mathrm{H}_{2} \mathrm{O} 0.5 \mathrm{~g}$, $\mathrm{K}_{2} \mathrm{HPO}_{4} 1 \mathrm{~g}, \mathrm{FeSO}_{4} \cdot 7 \mathrm{H}_{2} \mathrm{O} 0.01 \mathrm{~g}, \mathrm{KCl} 0.5 \mathrm{~g}$ in 1 liter of distilled water, $\mathrm{pH}$ 6.0) and chitinase detection medium (chitin
$5 \mathrm{~g}, \mathrm{MgSO}_{4} \cdot 7 \mathrm{H}_{2} \mathrm{O} 0.1 \mathrm{~g}, \mathrm{NH}_{4} \mathrm{NO}_{3} 3 \mathrm{~g}, \mathrm{KH}_{2} \mathrm{PO}_{4} 2 \mathrm{~g}$ in 1 liter of distilled water, $\mathrm{pH} 6.0$ ) were used to ferment Trichoderma strains. Corn meal dextrose agar medium (CMD, $30 \mathrm{~g}$ corn flour, $18 \mathrm{~g}$ glucose, and $18 \mathrm{~g}$ agar; dilute the volume to $1 \mathrm{~L}$ with water) and synthetic low nutrient agar medium (SNA, $1.0 \mathrm{~g}$ $\mathrm{KH}_{2} \mathrm{PO}_{4}, 10.5 \mathrm{~g} \mathrm{KCl}, 1.0 \mathrm{~g} \mathrm{KNO} 3,0.5 \mathrm{~g} \mathrm{MgSO} 4,0.2 \mathrm{~g}$ glucose, $0.2 \mathrm{~g}$ sucrose, and $18 \mathrm{~g}$ agar; dilute it to $1 \mathrm{~L}$ with water) were used for the morphological identification of Trichoderma strains.

2.2. Collection of Samples and Isolation of Trichoderma. A total of 1018 samples of the rhizosphere soil and plants of cultivated crops from different ecological habitats, and decaying woods were collected from China. All samples were placed into sterile plastic bags in an icebox, transported to the laboratory in an icebox, and stored at $4^{\circ} \mathrm{C}$ for further use. Add $10 \mathrm{~g}$ of soil into $90 \mathrm{~mL}$ sterile water, shook for $30 \mathrm{~min}\left(200 \mathrm{r} \mathrm{min}^{-1}\right)$, and then dilute to $10^{3}$-fold. Fresh plant samples and rotten woods were surface-disinfected by $70 \%$ alcohol for $30 \mathrm{~s}$, ground in $1 \times$ PBS buffer, and diluted to 100 -fold. The solutions $(100 \mu \mathrm{L})$ were added to the surface of TSM for the isolation of Trichoderma spp. Each sample was performed in triplicate. Morphologically different colonies were selected, transferred onto PDA medium, and purified by a single spore isolation [26]. All purified strains were maintained on PDA slants at $4^{\circ} \mathrm{C}$ for further use.

2.3. Inhibitory Effect of Trichoderma Strains on the Pathogenic Fungi. The antagonistic ability of all Trichoderma strains against pathogenic fungi was evaluated by a dual culture method. Five-millimeter diameter mycelial disks from Trichoderma strains and pathogenic fungi were transferred onto the border of PDA plate opposed to each other with a distance of $50 \mathrm{~mm}$ on Petri dishes (diameter, $90 \mathrm{~mm}$ ) and incubated at $28^{\circ} \mathrm{C}$ for 7 days. The individual cultures of the pathogenic fungi were used as controls. The percentage of growth inhibition (PI) was calculated using the following equation: PI (\%) $=[(C-T) / C] \times 100$, where $C$ represents radial growth of control mycelial and $T$ represents radial growth of the treatment mycelial. Each treatment was performed in triplicate.

2.4. Effect of Trichoderma Strains on Seed Germination. Five crops (Supplementary Table S1), including rice, tomato, melon, cucumber, and pakchoi, were used to measure the effect of Trichoderma strains on seed germination. Uniform size 50 seeds of each crop were surface-disinfected by $75 \%$ ethanol for $1 \mathrm{~min}$ and $0.5 \% \mathrm{NaClO}$ for $5 \mathrm{~min}$ and washed five times with sterile water. The seeds were soaked in Petri dishes containing $50 \mathrm{~mL}$ of Trichoderma strains spore suspension $\left(10^{5}\right.$ spores $\left.\mathrm{mL}^{-1}\right)$ for $2 \mathrm{~h}$, transferred into new petri dishes covered with a layer of cotton and a filter paper, and cultured for 7 days at $28^{\circ} \mathrm{C}$ under the conditions of $12 / 12 \mathrm{~h}$ light/dark. The seeds treated with an equivalent volume of sterile water were used as control. The seed germination rate was calculated using the following equation: seed germination rate $(\%)=$ number of germinated seeds/number of total seeds tested $\times 100$. The experiment was performed in triplicate.

2.5. Determination of Growth Promoting Effect of Trichoderma Strains. The root growth promotion experiment was performed at $28^{\circ} \mathrm{C}$ under the conditions of $12 / 12 \mathrm{~h}$ light/dark 
alternation with $80 \%$ relative humidity in a greenhouse. Uniform size seedlings of watermelon, chili, eggplant, and tomato were irrigated with a $100 \mathrm{~mL}$ spore suspension $\left(10^{5}\right.$ spores $\mathrm{mL}^{-1}$ ) of the Trichoderma strains. The seedlings treated with water were used as control. After 15 days, the seedlings were harvested, and the roots and aboveground seedlings were separated with scissors. The root length of seedlings was measured. The experiment was carried out in triplicate.

\subsection{Determination of the Colonization Ability of Trichoderma} Strains. The spore suspension $\left(10^{7}\right.$ spores $\left.\mathrm{mL}^{-1}\right)$ of the Trichoderma strains was added into sterilized composite soil containing vermiculite, matrix, and soil $(1: 3: 7)$ and adjusted to a final concentration of $10^{4}$ spores $\mathrm{g}^{-1}$. Sterilized distilled water was used as the control. The Trichoderma-inoculated and Trichoderma-uninoculated soils were placed into sterile glass test tubes (height, $25 \mathrm{~cm}$; inner diameter, $2 \mathrm{~cm}$ ), and then, a cucumber seed was planted inside. All tubes were inserted with a cotton ball, sealed with tin foil, and placed in a plant growth chamber at $28^{\circ} \mathrm{C}$ under the conditions of $12 / 12 \mathrm{~h}$ light/dark alternation. After 15 days, the Trichoderma populations in the rhizosphere soil and roots endoderm of cucumber were calculated by a dilution plate method [27] (thirty seedlings for each treatment). The experiment was performed in triplicate.

\subsection{Determination of $\beta-1,3-$ Glucanase and Chitinase Activity} of Trichoderma Strains. For the determination of $\beta$-1,3-glucanase activity, the Trichoderma strain was incubated in synthetic medium and cultured at $28^{\circ} \mathrm{C}$ with shaking at $180 \mathrm{rpm}$ for 3 days. Medium without Trichoderma spp. was used as control. Approximately $1 \mathrm{~mL}$ of the culture filtrate was used to assay activity of $\beta$-1,3-glucanase using the 3,5-dinitrosalicylic acid colorimetric method [28]. For the determination of chitinase activity, Trichoderma strain was incubated in chitinase detection medium and cultured at $28^{\circ} \mathrm{C}$ with shaking at $180 \mathrm{rpm}$ for 3 days. Colloidal chitin was prepared according to the method described by Roberts and Selitrennikoff [29]. The assay was performed in $10 \mathrm{~mL}$ tubes containing $1 \mathrm{~mL}$ $1 \%$ colloidal chitin, $1.5 \mathrm{~mL} 50 \mathrm{mM}$ acetate buffer $\mathrm{pH}=5.0$, and $1 \mathrm{~mL}$ suspension, the mixture was incubated at $40^{\circ} \mathrm{C}$ for $1 \mathrm{~h}$, and the chitinase activity was determined basing the standard curves of $\mathrm{N}$-acetyl-D-glucosamine (GlcNAc) measured at $540 \mathrm{~nm}$ absorbance. Enzyme bioactivity was calculated as follows: enzyme bioactivity $(\mathrm{U} / \mathrm{mL})=[(\mathrm{A} 1-\mathrm{A} 2)+\mathrm{b} 1] \times d /$ $(\mathrm{K} 1 \times \mathrm{V} 1 \times \mathrm{T} 1)$, where $\mathrm{A} 1$ represents $\mathrm{OD}_{540}$ of samples, $\mathrm{A} 2$ represents $\mathrm{OD}_{540}$ of control, b1 represents the $y$-intercept of standard curves, $d$ represents dilution rate of suspension, K1 represents the slope of standard curves, V1 represents the volume of mixture $(\mathrm{mL})$, and $\mathrm{T} 1$ represents reaction time $(\mathrm{h})$. Each treatment was performed in triplicate.

2.8. Identification of Trichoderma Strains. The morphological characteristics of conidia, phialide, conidiophore, and chlamydospores and the colony growth patterns of Trichoderma strains cultured on PDA, SNA, and CMD media were observed according to the description of Gams and Bissett [30]. For molecular identification, genomic DNAs of Trichoderma strains were extracted using the method of cetyltrimethylammonium ammonium bromide (CTAB) as described by Ihrmark et al. [31]. The tef- 1 gene was amplified with primers tef1-728F ( $5^{\prime}$-CATCGAGAAGTTCGAG AAGG- $\left.3^{\prime}\right)$ and tef1- $R$ ( $5^{\prime}$-GCCATCCTTGGGAGATACC AGC- $\left.3^{\prime}\right)$, and ITS region was amplified with primers ITS4 $\left(5^{\prime}\right.$-TCCTCCGCTTATTGATATGC- $\left.3^{\prime}\right)$ and ITS5 $\left(5^{\prime}\right.$ GGAAGTAAAAGTCGTAACAAGG-3'). The PCR products were cloned into the Ti-19 vector and sequenced by the Sangon Biotechnology Co., Ltd. (Shanghai, China). All sequences from Trichoderma strains were aligned and spliced through "tef-1+ITS region" using MAFFT v7.215 [32]. The best substitution model $(\mathrm{GTR}+\mathrm{F}+\mathrm{I}+\mathrm{G} 4)$ was evaluated with IQ-TREE software using the ultrafast bootstrap method with 10,000 replicates. The phylogenetic tree was constructed based on tef- 1 gene and ITS region for the molecular identification of the Trichoderma species.

2.9. Statistical Analyses. All experiments were repeated three times. The data were analyzed using IBM SPSS Statistics 21.0 software (IBM Corp., Armonk, NY, USA) using one-way analysis of variance (ANOVA). Means of treatment were compared using the least significant difference (LSD) test at $P<0.05$ and separated by superscript letters.

\section{Results}

3.1. Screening the Antagonistic Activity of Trichoderma Strains. A total of 1308 Trichoderma strains were obtained by the dilution plate method and single spore isolation method, including 1018 strains from 1018 rhizosphere soil samples, 205 strains from 45 rotten wood samples, and 86 strains from 16 plant samples. The dual culture test showed that 49 Trichoderma strains had good inhibitory effects against F. oxysporum (FOC), C. gloeosporioides (CG), and B. cinerea (BC), and their PIs were all exceeded $85 \%$ (Table 1). These 49 strains used for further experiments.

3.2. Promotion Effect of Trichoderma Strains on Seed Germination and Root Growth. The germination test showed that 13 strains (GZ070, HL100, HL119, HL135, HN059, JX013, SC012, XJ035, NX043, QH060, XJ087, SC098, and SC101) significantly promoted the seed germination of the five plants compared with the control. Among them, HL100 strain showed the best promotion effects on seed germination of rice, cucumber, and pakchoi, with increased germination rates of $12.17 \%, 13.23 \%$, and $27.54 \%$, respectively. The XM002-21 and XJ087 strains showed the highest promotion effects on seed germination of melon and tomato, with increased germination rates of $12.55 \%$ and $41.94 \%$, respectively (Table 2 ).

The 13 Trichoderma strains that significantly promoted the seed germination were further tested for their effect on root growth of watermelon, chili, eggplant, and tomato seedlings. In greenhouse experiment, all strains showed a promotion effect on root growth of chili seedlings, and among them, HL100 strain showed maximum increase $12.17 \%$ in root length compared to control. Three strains (GZ070, HL100, and HN059) significantly promoted the root growth of watermelon seedlings. HN059 strain showed maximum increase of $18.81 \%$ in root length compared to control. Trichoderma strains GZ070, HL100, HN059, JX013, XJ087, and NX043 strains 
TABLE 1: The region of the isolates which were screened in dual culture and its PI to three pathogens.

\begin{tabular}{|c|c|c|c|c|}
\hline \multirow{2}{*}{ Code } & \multirow{2}{*}{ Region } & \multicolumn{3}{|c|}{ PI (\%) } \\
\hline & & FOC & CG & $\mathrm{BC}$ \\
\hline HL003 & Hegang, Heilongjiang & $85.13 \pm 2.35$ & $86.15 \pm 1.54$ & $90.56 \pm 0.96$ \\
\hline HN071 & Ledong, Hainan & $89.23 \pm 1.54$ & $88.72 \pm 2.35$ & $89.74 \pm 1.18$ \\
\hline SC006 & Panzhihua, Sichuan & $86.15 \pm 6.71$ & $97.95 \pm 0.89$ & $89.33 \pm 6.11$ \\
\hline SC017 & Panzhihua, Sichuan & $86.67 \pm 2.35$ & $93.85 \pm 1.54$ & $89.33 \pm 2.31$ \\
\hline HN059 & Ledong, Hainan & $85.13 \pm 2.35$ & $91.28 \pm 0.89$ & $88.89 \pm 1.48$ \\
\hline JX013 & Pingxiang, Jiangxi & $85.13 \pm 3.20$ & $88.21 \pm 3.55$ & $88.51 \pm 5.27$ \\
\hline HL007 & Hegang, Heilongjiang & $86.15 \pm 1.54$ & $91.28 \pm 1.78$ & $88.33 \pm 0.22$ \\
\hline HL101 & Jiamusi, Heilongjiang & $85.13 \pm 0.89$ & $88.21 \pm 0.89$ & $88.33 \pm 3.89$ \\
\hline HN046 & Danzhou, Hainan & $86.67 \pm 0.89$ & $89.74 \pm 0.89$ & $88.03 \pm 1.48$ \\
\hline HL008 & Hailun, Heilongjiang & $90.51 \pm 0.44$ & $95.49 \pm 0.18$ & $88.00 \pm 0.92$ \\
\hline JX002 & Pingxiang, Jiangxi & $85.64 \pm 4.95$ & $91.28 \pm 0.89$ & $87.03 \pm 2.25$ \\
\hline GX004 & Guilin, Guangxi & $88.21 \pm 0.89$ & $93.33 \pm 0.89$ & $87.03 \pm 5.94$ \\
\hline HL137 & Hailun, Heilongjiang & $86.15 \pm 1.54$ & $90.26 \pm 3.20$ & $87.03 \pm 2.25$ \\
\hline NM023 & Chifeng, Neimeng & $85.13 \pm 2.35$ & $91.28 \pm 3.55$ & $85.06 \pm 1.99$ \\
\hline HL119 & Yichun, Heilongjiang & $85.13 \pm 3.87$ & $85.13 \pm 0.89$ & $86.67 \pm 2.31$ \\
\hline FJ090 & Ningde, Fujian & $86.15 \pm 1.54$ & $95.90 \pm 0.89$ & $86.67 \pm 2.31$ \\
\hline HL092 & Daqing, Heilongjiang & $90.82 \pm 0.09$ & $93.33 \pm 0.89$ & $86.67 \pm 2.31$ \\
\hline ZJ019 & Wenzhou, Zhejiang & $88.72 \pm 3.87$ & $88.21 \pm 3.20$ & $86.50 \pm 2.34$ \\
\hline HN027 & Danzhou, Hainan & $85.13 \pm 0.89$ & $91.28 \pm 0.89$ & $86.32 \pm 3.92$ \\
\hline SX001 & Changzhi, Shanxi & $86.15 \pm 1.54$ & $88.72 \pm 1.78$ & $85.47 \pm 1.48$ \\
\hline HL144 & Hegang, Heilongjiang & $87.69 \pm 1.54$ & $92.82 \pm 2.35$ & $85.73 \pm 4.49$ \\
\hline HL018 & Jiamusi, Heilongjiang & $85.13 \pm 0.89$ & $91.79 \pm 0.89$ & $85.73 \pm 5.94$ \\
\hline HL132 & Hegang, Heilongjiang & $86.67 \pm 4.70$ & $89.74 \pm 1.78$ & $85.73 \pm 5.94$ \\
\hline HL131 & Hegang, Heilongjiang & $88.72 \pm 0.89$ & $91.28 \pm 2.35$ & $85.73 \pm 5.94$ \\
\hline FJ065 & Ningde, Fujian & $87.18 \pm 3.87$ & $91.28 \pm 2.35$ & $85.73 \pm 4.49$ \\
\hline SC011 & Panzhihua, Sichuan & $90.77 \pm 3.08$ & $93.85 \pm 1.54$ & $85.33 \pm 2.31$ \\
\hline SC018 & Panzhihua, Sichuan & $86.15 \pm 1.54$ & $96.41 \pm 3.55$ & $85.33 \pm 2.31$ \\
\hline SC013 & Panzhihua, Sichuan & $89.74 \pm 3.20$ & $91.79 \pm 0.89$ & $85.33 \pm 6.11$ \\
\hline FJ058 & Ningde, Fujian & $85.13 \pm 0.89$ & $94.36 \pm 1.78$ & $85.33 \pm 2.31$ \\
\hline HL015 & Daqing, Heilongjiang & $85.64 \pm 0.89$ & $91.79 \pm 0.89$ & $85.33 \pm 2.31$ \\
\hline HL100 & Hailun, Heilongjiang & $90.26 \pm 3.20$ & $95.90 \pm 0.89$ & $85.33 \pm 4.62$ \\
\hline FJ034 & Fuzhou, Fujian & $85.13 \pm 1.78$ & $85.64 \pm 4.95$ & $85.16 \pm 4.67$ \\
\hline LN005 & Dalian, Liaoning & $86.67 \pm 1.78$ & $87.18 \pm 0.89$ & $85.06 \pm 3.98$ \\
\hline XM002-21 & Danzhou, Hainan & $86.10 \pm 0.09$ & $86.15 \pm 1.54$ & $85.06 \pm 5.27$ \\
\hline HL048 & Daqing, Heilongjiang & $92.82 \pm 0.89$ & $96.41 \pm 0.89$ & $85.20 \pm 2.08$ \\
\hline SC010 & Panzhihua, Sichuan & $87.69 \pm 2.66$ & $90.77 \pm 1.54$ & $86.13 \pm 3.70$ \\
\hline HL135 & Hegang, Heilongjiang & $90.77 \pm 1.54$ & $90.26 \pm 3.20$ & $85.20 \pm 2.12$ \\
\hline SC012 & Chengdu, Sichuan & $90.21 \pm 0.98$ & $94.87 \pm 3.20$ & $85.33 \pm 6.11$ \\
\hline HN018 & Danzhou, Hainan & $90.26 \pm 2.35$ & $89.23 \pm 1.54$ & $85.21 \pm 3.39$ \\
\hline GZ070 & Guiyang, Guizhou & $90.15 \pm 2.32$ & $92.31 \pm 1.54$ & $86.50 \pm 4.67$ \\
\hline FJ087 & Fuzhou, Fujian & $88.72 \pm 2.35$ & $94.97 \pm 0.71$ & $85.33 \pm 3.06$ \\
\hline SC019 & Panzhihua, Sichuan & $89.74 \pm 0.89$ & $96.92 \pm 2.66$ & $85.33 \pm 7.02$ \\
\hline JS016 & Xuzhou, Jiangsu & $85.08 \pm 0.80$ & $89.74 \pm 2.35$ & $91.11 \pm 1.92$ \\
\hline
\end{tabular}


TABLE 1: Continued.

\begin{tabular}{lcccc}
\hline Code & Region & PI (\%) & CG & BC \\
\hline BJ006 & Haidian, Beijing & $85.13 \pm 2.35$ & $86.67 \pm 9.40$ & $90.00 \pm 3.33$ \\
QH060 & Haixi, Qinghai & $87.79 \pm 0.18$ & $87.69 \pm 1.54$ & $85.13 \pm 2.35$ \\
SC101 & Guangyuan, Sichuan & $86.26 \pm 0.18$ & $85.13 \pm 0.89$ & $85.13 \pm 0.89$ \\
NX043 & Qinghai, Ningxia & $85.13 \pm 0.89$ & $85.12 \pm 0.89$ & $89.23 \pm 1.54$ \\
XJ035 & Yili, Xinjiang & $89.38 \pm 0.27$ & $85.13 \pm 0.89$ & $86.67 \pm 1.78$ \\
SC098 & Guangyuan, Sichuan & $87.74 \pm 0.09$ & $85.17 \pm 2.35$ & $86.15 \pm 0.27$ \\
XJ087 & Kuerle, Xinjiang & $86.15 \pm 0.27$ & $85.13 \pm 0.89$ & $85.13 \pm 0.89$ \\
\hline
\end{tabular}

Data represent the mean \pm SD ( $n=3)$. FOC: Fusarium oxysporum; CG: Colletotrichum gloeosporioides; BC: Botrytis cinerea; PI (\%): percentage of growth inhibition.

TABLE 2: The germination rate of 5 kinds of seeds after Trichoderma treatment.

\begin{tabular}{lccccc}
\hline Code & Rice & Cucumber & $\begin{array}{c}\text { Seed germination rates (\%) } \\
\text { Tomato }\end{array}$ & Melon & Pakchoi \\
\hline GZ070 & $83.14 \pm 1.97^{\mathrm{a}}$ & $85.56 \pm 10.18^{\mathrm{a}}$ & $44.00 \pm 14.37^{\mathrm{d}, \mathrm{e}}$ & $83.33 \pm 10.00^{\mathrm{a}}$ & $71.99 \pm 4.41^{\mathrm{b}}$ \\
HL100 & $94.06 \pm 3.98^{\mathrm{a}}$ & $90.56 \pm 7.97^{\mathrm{a}}$ & $49.91 \pm 15.25^{\mathrm{b}, \mathrm{c}, \mathrm{e}}$ & $80.83 \pm 0.72^{\mathrm{a}}$ & $99.48 \pm 0.90^{\mathrm{a}}$ \\
HL119 & $89.62 \pm 4.36^{\mathrm{a}}$ & $89.64 \pm 7.50^{\mathrm{a}}$ & $43.31 \pm 1.30^{\mathrm{d}, \mathrm{e}}$ & $85.29 \pm 7.50^{\mathrm{a}}$ & $97.68 \pm 0.86^{\mathrm{a}}$ \\
HL135 & $93.39 \pm 3.26^{\mathrm{a}}$ & $87.30 \pm 10.13^{\mathrm{a}}$ & $48.72 \pm 15.06^{\mathrm{c}, \mathrm{d}, \mathrm{e}}$ & $78.89 \pm 8.67^{\mathrm{a}}$ & $98.93 \pm 0.93^{\mathrm{a}}$ \\
HN059 & $89.70 \pm 3.14^{\mathrm{a}}$ & $79.21 \pm 7.40^{\mathrm{a}}$ & $45.93 \pm 8.41^{\mathrm{d}, \mathrm{e}}$ & $80.43 \pm 3.25^{\mathrm{a}}$ & $94.88 \pm 2.46^{\mathrm{a}}$ \\
JX013 & $89.59 \pm 7.09^{\mathrm{a}}$ & $78.92 \pm 13.81^{\mathrm{a}}$ & $48.03 \pm 5.85^{\mathrm{c}, \mathrm{d}, \mathrm{e}}$ & $77.14 \pm 8.51^{\mathrm{a}}$ & $71.96 \pm 5.24^{\mathrm{b}}$ \\
SC012 & $92.81 \pm 3.92^{\mathrm{a}}$ & $88.80 \pm 4.74^{\mathrm{a}}$ & $43.99 \pm 18.12^{\mathrm{d}, \mathrm{e}}$ & $86.59 \pm 11.48^{\mathrm{a}}$ & $99.00 \pm 1.72^{\mathrm{a}}$ \\
XJ035 & $83.78 \pm 19.05^{\mathrm{a}}$ & $82.22 \pm 16.44^{\mathrm{a}}$ & $72.00 \pm 16.00^{\mathrm{a}, \mathrm{b}, \mathrm{c}}$ & $76.81 \pm 9.77^{\mathrm{a}}$ & $78.67 \pm 13.32^{\mathrm{b}}$ \\
NX043 & $82.33 \pm 15.53^{\mathrm{a}}$ & $80.00 \pm 15.28^{\mathrm{a}}$ & $74.67 \pm 2.15^{\mathrm{a}, \mathrm{b}}$ & $82.22 \pm 10.09^{\mathrm{a}}$ & $81.11 \pm 7.37^{\mathrm{b}}$ \\
QH060 & $87.00 \pm 7.55^{\mathrm{a}}$ & $85.56 \pm 6.94^{\mathrm{a}}$ & $88.00 \pm 2.00^{\mathrm{a}}$ & $77.78 \pm 13.47^{\mathrm{a}}$ & $83.33 \pm 3.06^{\mathrm{b}}$ \\
XJ087 & $87.75 \pm 8.49^{\mathrm{a}}$ & $82.22 \pm 5.09^{\mathrm{a}}$ & $83.33 \pm 5.77^{\mathrm{a}}$ & $81.11 \pm 1.92^{\mathrm{a}}$ & $80.00 \pm 3.46^{\mathrm{b}}$ \\
SC098 & $87.33 \pm 7.02^{\mathrm{a}}$ & $85.56 \pm 8.39^{\mathrm{a}}$ & $66.11 \pm 10.46^{\mathrm{a}, \mathrm{b}, \mathrm{c}, \mathrm{d}, \mathrm{e}}$ & $79.33 \pm 4.62^{\mathrm{a}}$ & $76.00 \pm 10.58^{\mathrm{b}}$ \\
SC101 & $82.34 \pm 12.17^{\mathrm{a}}$ & $79.56 \pm 1.92^{\mathrm{a}}$ & $69.33 \pm 1.15^{\mathrm{a}, \mathrm{b}, \mathrm{c}, \mathrm{d}}$ & $82.22 \pm 11.71^{\mathrm{a}}$ & $73.67 \pm 11.72^{\mathrm{b}}$ \\
CK & $81.91 \pm 17.41^{\mathrm{a}}$ & $77.33 \pm 8.03^{\mathrm{a}}$ & $41.39 \pm 12.41^{\mathrm{e}}$ & $76.34 \pm 4.93^{\mathrm{a}}$ & $71.94 \pm 7.25^{\mathrm{b}}$ \\
\hline
\end{tabular}

Germination rates of seed were measured at 7 days, where seeds were treated by $10^{5}$ spore $\mathrm{mL}^{-1}$ suspension in 2 hours. "CK" means to treat seeds with sterile water. Data represent the mean \pm SD $(n=3)$. Different letters indicate that the differences are significant $(P<0.05)$ using Duncan's multiple range test.

and HL119, HN059, SC012, XJ035, SC098, and SC101 were found to promote the root growth of eggplant and tomato seedlings, respectively. The highest increase in root length of eggplant (40.99\%) and tomato plants (34.68\%) was recorded by GZ070 and SC098 strains, respectively (Table 3).

3.3. Colonization Ability of Trichoderma Strains. The colonization of GZ070, HL100, and JX013 strains in rhizosphere soil was higher than that of other strains, which were 8.30 $\times 10^{4}, 1.50 \times 10^{5}$, and $1.56 \times 10^{5} \mathrm{CFU} \mathrm{g}^{-1}$, respectively. In the root endoderm of cucumber, the colonization of GZ070, HL100, and QH060 strains was higher than that of other strains, showing $7.67 \times 10^{4}, 1.20 \times 10^{5}$, and $8.00 \times 10^{4}$ $\mathrm{CFU} \mathrm{g}^{-1}$, respectively (Figure 1 ).

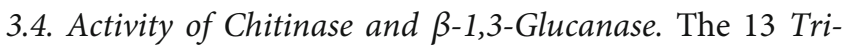
choderma strains were used to measure the activities of chit- inase and $\beta$-1,3-glucanase. The results showed that these strains possessed a wide range of activity of chitinase and $\beta$-1,3-glucanase (Table 4). SC012 strain exhibited the highest chitinase activity $\left(0.154 \mathrm{U} \mathrm{mL}^{-1}\right)$. NX043 and XJ087 strains showed the highest $\beta$-1,3-glucanase activity. The lowest chitinase activity $\left(0.041 \mathrm{U} \mathrm{mL}^{-1}\right)$ and $\beta$-1,3-glucanase activity $\left(0.1765 \mathrm{U} \mathrm{mL}^{-1}\right)$ were shown by SC098 and XJ035 strains, respectively.

3.5. Detection of Antimicrobial Spectrum of Trichoderma. The results showed that 13 Trichoderma strains exhibited significant inhibitory effects on 9 kinds of pathogenic fungi (Table 5). The inhibition rates of 13 Trichoderma strains to FT and MO were all over 80\% (80.81-88.37\%). NX043 strain had the highest inhibition rate on FT (88.37\%), and HL100 strain had the highest inhibition rate to MO (87.50\%). However, the inhibition rate of 13 Trichoderma strains on BT was lower than that of other pathogenic fungi (59.49-70.26\%). 
TABLE 3: Root length of different crops treated with a spore suspension at 15 days.

\begin{tabular}{|c|c|c|c|c|}
\hline \multirow{2}{*}{ Code } & \multicolumn{4}{|c|}{ Length of roots $(\mathrm{cm})$} \\
\hline & Watermelon & Chili & Eggplant & Tomato \\
\hline GZ070 & $11.71 \pm 0.18^{\mathrm{a}, \mathrm{b}, \mathrm{c}}$ & $9.56 \pm 0.54^{\mathrm{b}, \mathrm{c}, \mathrm{d}}$ & $12.88 \pm 2.55^{\mathrm{a}}$ & $3.74 \pm 0.49^{\mathrm{e}, \mathrm{f}, \mathrm{g}, \mathrm{h}}$ \\
\hline HL100 & $12.26 \pm 0.73^{\mathrm{a}, \mathrm{b}, \mathrm{c}}$ & $11.85 \pm 0.83^{\mathrm{a}, \mathrm{b}}$ & $10.48 \pm 1.06^{\mathrm{a}, \mathrm{b}, \mathrm{c}, \mathrm{d}, \mathrm{e}}$ & $3.60 \pm 0.37^{\mathrm{g}, \mathrm{h}}$ \\
\hline HL119 & $9.36 \pm 1.00^{\mathrm{h}}$ & $11.08 \pm 0.82^{\mathrm{a}, \mathrm{b}, \mathrm{c}}$ & $9.47 \pm 2.13^{\mathrm{i}, \mathrm{j}}$ & $5.03 \pm 0.71^{\mathrm{a}, \mathrm{b}, \mathrm{c}, \mathrm{d}}$ \\
\hline HL135 & $11.20 \pm 0.57^{\mathrm{c}, \mathrm{d}, \mathrm{e}, \mathrm{f}, \mathrm{g}}$ & $9.72 \pm 0.74^{\mathrm{b}, \mathrm{c}, \mathrm{d}}$ & $9.54 \pm 1.29^{\mathrm{h}, \mathrm{i}, \mathrm{j}}$ & $2.98 \pm 0.16^{\mathrm{h}}$ \\
\hline HN059 & $13.03 \pm 1.51^{\mathrm{a}}$ & $11.28 \pm 1.38^{\mathrm{a}, \mathrm{b}}$ & $10.16 \pm 0.55^{\mathrm{c}, \mathrm{d}, \mathrm{e}, \mathrm{f}, \mathrm{g}}$ & $4.10 \pm 0.29^{\mathrm{e}, \mathrm{f}, \mathrm{g}, \mathrm{h}}$ \\
\hline JX013 & $9.71 \pm 0.54^{\mathrm{h}}$ & $10.33 \pm 0.57^{\mathrm{a}, \mathrm{b}, \mathrm{c}, \mathrm{d}}$ & $10.91 \pm 1.02^{\mathrm{a}, \mathrm{b}, \mathrm{c}, \mathrm{d}}$ & $3.73 \pm 0.46^{\mathrm{f}, \mathrm{g}, \mathrm{h}}$ \\
\hline SC012 & $11.33 \pm 1.10^{\mathrm{b}, \mathrm{c}, \mathrm{d}, \mathrm{e}, \mathrm{f}}$ & $10.19 \pm 0.95^{\mathrm{a}, \mathrm{b}, \mathrm{c}, \mathrm{d}}$ & $9.24 \pm 0.66^{\mathrm{h}, \mathrm{i}, \mathrm{j}}$ & $5.02 \pm 0.54^{\mathrm{a}, \mathrm{b}}$ \\
\hline XJ035 & $10.69 \pm 0.49^{\mathrm{c}, \mathrm{d}, \mathrm{e}, \mathrm{f}, \mathrm{g}}$ & $10.96 \pm 0.90^{\mathrm{a}, \mathrm{b}, \mathrm{c}, \mathrm{d}}$ & $8.24 \pm 0.70^{\mathrm{h}, \mathrm{i}, \mathrm{j}}$ & $4.76 \pm 0.54^{\mathrm{b}, \mathrm{c}, \mathrm{d}}$ \\
\hline NX043 & $11.65 \pm 1.66^{\mathrm{b}, \mathrm{c}, \mathrm{d}, \mathrm{e}, \mathrm{f}, \mathrm{g}}$ & $10.51 \pm 0.68^{\mathrm{a}, \mathrm{b}, \mathrm{c}, \mathrm{d}}$ & $9.39 \pm 1.58^{\mathrm{e}, \mathrm{f}, \mathrm{g}, \mathrm{h}, \mathrm{i}, \mathrm{j}}$ & $3.37 \pm 0.38^{h}$ \\
\hline QH060 & $11.50 \pm 0.99^{\mathrm{c}, \mathrm{d}, \mathrm{e}, \mathrm{f}, \mathrm{g}}$ & $9.20 \pm 0.51^{\mathrm{a}, \mathrm{b}, \mathrm{c}, \mathrm{d}}$ & $8.45 \pm 0.57^{h, i, j}$ & $3.43 \pm 0.61^{\mathrm{f}, \mathrm{g}, \mathrm{h}}$ \\
\hline XJ087 & $10.25 \pm 0.58^{\mathrm{g}, \mathrm{h}}$ & $9.79 \pm 0.78^{\mathrm{a}, \mathrm{b}, \mathrm{c}, \mathrm{d}}$ & $11.33 \pm 0.38^{\mathrm{a}, \mathrm{b}, \mathrm{c}, \mathrm{d}, \mathrm{e}}$ & $3.35 \pm 0.33^{\mathrm{f}, \mathrm{g}, \mathrm{h}}$ \\
\hline SC098 & $10.18 \pm 0.88^{e, f, g, h}$ & $8.96 \pm 0.76^{\mathrm{b}, \mathrm{c}, \mathrm{d}}$ & $8.45 \pm 0.87^{\mathrm{i}, \mathrm{j}}$ & $5.40 \pm 0.46^{\mathrm{a}}$ \\
\hline SC101 & $9.99 \pm 0.83^{\mathrm{f}, \mathrm{g}, \mathrm{h}}$ & $9.88 \pm 0.65^{\mathrm{a}, \mathrm{b}}$ & $7.00 \pm 0.32^{\mathrm{k}}$ & $4.42 \pm 0.37^{\mathrm{d}, \mathrm{e}, \mathrm{g}, \mathrm{f}}$ \\
\hline $\mathrm{CK}$ & $11.26 \pm 0.18^{\mathrm{a}, \mathrm{b}}$ & $9.34 \pm 0.38^{\mathrm{d}}$ & $9.63 \pm 0.15^{\mathrm{f}, \mathrm{g}, \mathrm{h}, \mathrm{i}, \mathrm{j}}$ & $3.93 \pm 0.14^{\mathrm{f}, \mathrm{g}, \mathrm{h}}$ \\
\hline
\end{tabular}

The concentration of the conidial suspension was $10^{5}$ spores $\mathrm{mL}^{-1}$. "CK" means to treat seeds with sterile water. Data represent the mean $\pm \mathrm{SD}(n=3)$. Different letters indicate that the differences are significant $(P<0.05)$ using Duncan's multiple range test.

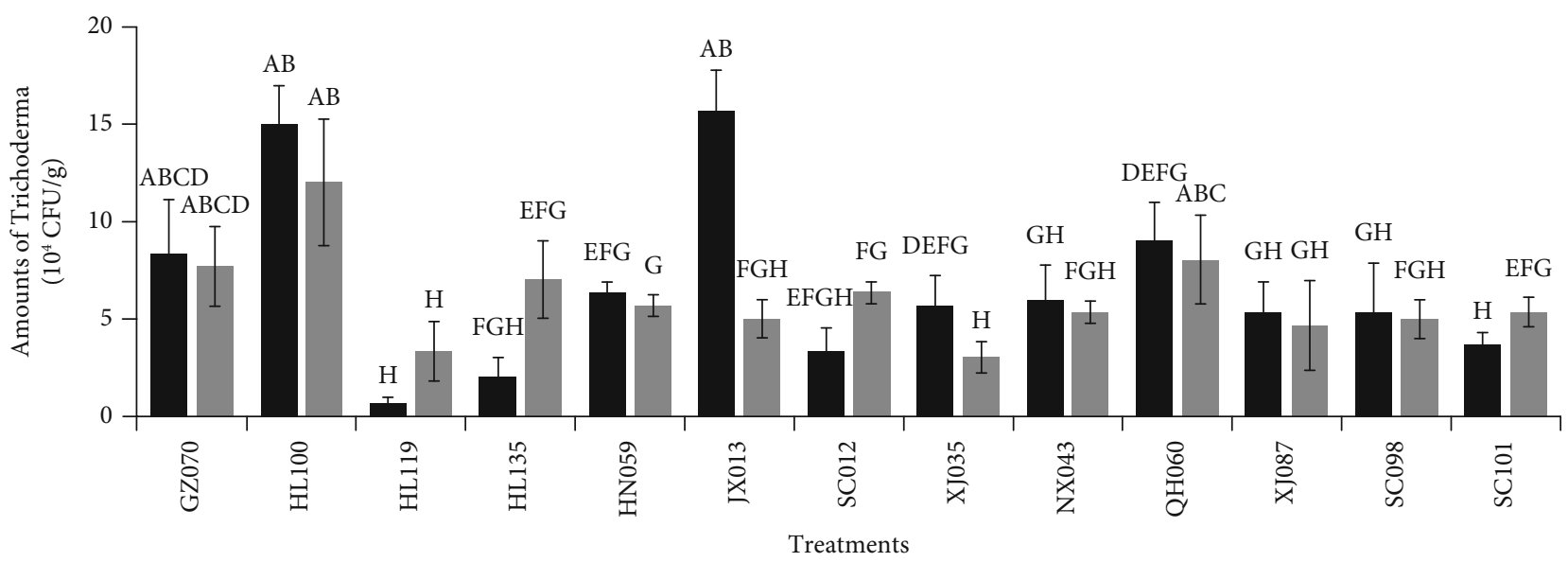

Rhizosphere soil

Endosphere in roots

FIGURE 1: Determination of colonization ability of Trichoderma on cucumber seedlings. Data represent the mean \pm SD $(n=3)$. Different letters indicate that the differences are significant $(P<0.05)$ using Duncan's multiple range test.

3.6. Identification of Trichoderma Strains with Potential Agricultural Applications. All strains, except for SC098, showed the same morphological characteristics after growing on three kinds of medium for 7 days. These strains appeared as dark green colonies with a distinctive coconut odor on PDA plates, and they formed green conidial pustules on CMD medium and produced white, yellow, and green sorus, forming concentric zones on SNA plates (Figures 2(a)-2(e) and 3(a)-(e)). Conidia and chlamydospores are smooth, watered, and subglobose, and the branches were pyramidal and verticillate or paired lateral arising. Phialides were tended to cluster on branches. SC098 strain produced a diffuse yellow pigment on both sides of PDA plates, and green and yellow cottony sori were observed on CMD medium at $48 \mathrm{~h}$. The mycelia of the strains were wavy and grown floccose to arachnoid on SNA plates, and phialides were ampulliform (length, 5-6.5 $\mu \mathrm{m}$; widest point, 2.9-3.2 $\mu \mathrm{m})$, tending to cluster and to create a narrow neck at the top (Figures 2(f)-2(h) and 3(f)-(h)). A phylogenetic tree demonstrated that all the selected strains had two distinct clades. JX013, HN059, XJ097, QH060, HL100, HL119, HL135, SC012, NX043, SC101, GZ070, and XJ035 strains belonged to 
TABle 4: Chitinase and $\beta$-1,3-glucanase activity of Trichoderma isolates at 3 days in enzyme synthetic medium.

\begin{tabular}{lcc}
\hline Code & Chitinase $\left(\mathrm{U} \mathrm{mL}^{-1}\right)$ & $\beta-1,3$-Glucanase $\left(\mathrm{U} \mathrm{mL}^{-1}\right)$ \\
\hline GZ070 & $0.069 \pm 0.018^{\mathrm{g}, \mathrm{h}, \mathrm{i}}$ & $0.398 \pm 0.044^{\mathrm{b}, \mathrm{c}}$ \\
HL100 & $0.105 \pm 0.017^{\mathrm{b}, \mathrm{c}, \mathrm{d}, \mathrm{e}, \mathrm{f}}$ & $0.319 \pm 0.042^{\mathrm{b}, \mathrm{c}, \mathrm{d}}$ \\
HL119 & $0.112 \pm 0.018^{\mathrm{b}, \mathrm{c,d}, \mathrm{e}}$ & $0.397 \pm 0.022^{\mathrm{b}, \mathrm{c}}$ \\
HL135 & $0.081 \pm 0.006^{\mathrm{e}, \mathrm{f}, \mathrm{g}, \mathrm{h}}$ & $0.488 \pm 0002^{\mathrm{b}}$ \\
HN059 & $0.068 \pm 0.016^{\mathrm{g}, \mathrm{h}, \mathrm{i}}$ & $0.340 \pm 0.002^{\mathrm{b}, \mathrm{c}, \mathrm{d}}$ \\
JX013 & $0.082 \pm 0.001^{\mathrm{e}, \mathrm{f}, \mathrm{g}, \mathrm{h}}$ & $0.489 \pm 0.05^{\mathrm{b}}$ \\
SC012 & $0.154 \pm 0.013^{\mathrm{a}}$ & $0.3744 \pm 0.062^{\mathrm{b}, \mathrm{c}, \mathrm{d}}$ \\
XJ035 & $0.087 \pm 0.009^{\mathrm{d}, \mathrm{e}, \mathrm{f}, \mathrm{g}, \mathrm{h}}$ & $0.1765 \pm 0.038^{\mathrm{c,d}}$ \\
NX043 & $0.108 \pm 0.028^{\mathrm{b}, \mathrm{c}, \mathrm{d}, \mathrm{e}}$ & $0.8162 \pm 0.172^{\mathrm{a}}$ \\
QH060 & $0.126 \pm 0.009^{\mathrm{b}}$ & $0.2258 \pm 0.070^{\mathrm{b}, \mathrm{c}, \mathrm{d}}$ \\
XJ087 & $0.104 \pm 0.039^{\mathrm{b}, \mathrm{c}, \mathrm{d}, \mathrm{e}, \mathrm{f}}$ & $0.7993 \pm 0.199^{\mathrm{a}}$ \\
SC098 & $0.047 \pm 0.015^{\mathrm{i}}$ & $0.3814 \pm 0.048^{\mathrm{b}, \mathrm{c}, \mathrm{d}}$ \\
SC101 & $0.095 \pm 0.006^{\mathrm{c}, \mathrm{d}, \mathrm{e}, \mathrm{f}, \mathrm{g}}$ & $0.3170 \pm 0.08^{\mathrm{b}, \mathrm{c}, \mathrm{d}}$ \\
\hline
\end{tabular}

Data represent the mean $\pm \mathrm{SD}(n=3)$. Different letters indicate that the differences are significant $(P<0.05)$ using Duncan's multiple range test.

the Hamatum clade and had affinity to KP009011 (T. asperellum). SC098 strain was identified as T. afroharzianum, which was closely related to KP0699541 (T. afroharzianum) and belonged to the harzianum clade (Figure 4). Based on the morphological and molecular characteristics, the remaining 12 strains were identified as T. asperellum, and SC098 strain was identified as T. afroharzianum.

\section{Discussion}

Trichoderma grows rapidly and can quickly occupy the growth space of pathogenic fungi, which is one of the important mechanisms of their antimicrobial effect [19]. The competitive effect of Trichoderma has been widely reported. For example, T. asperellum (T3, T4, T15, and T19) and T. harzianum T6 showed effective inhibition on graminicola in the dual culture assay [33]; T. atroviride, T. harzianum, and T. viride showed strong inhibitory effects on Phytophthora, Botrytis cinerea, and Rhizoctonia solanacearum in competitive bioassay tests [34]. In this study, we found that the growth rate of Trichoderma was significantly faster than that of pathogenic fungi. It could be clearly observed that Trichoderma covered most parts of the plates, and some can even continue to grow on the colony of pathogenic fungi and then covered the entire colony, showing obvious competition.

The production of cell wall-degrading enzymes (CWDEs) and volatile antibiotics is key parameters for Trichoderma as a biocontrol agent [35]. Saravanakumar et al. proved that there was a positive correlation between the CWDs of Trichoderma strains and its antagonism to pathogens [15]. We found that 13 Trichoderma strains (PI > 85\%) with excellent antagonism to pathogens could secrete chitinase and $\beta$-1,3-glucanase, which were closely related to the cell wall composition of pathogens. Therefore, Trichoderma can not only compete with pathogens for space and nutrition but also degrade the cell walls of pathogens, deform, or even digest the hyphae, and inhibit the growth of pathogens. It has also been reported that the cell wall degrading enzymes such as chitinase and glucanase secreted by Trichoderma also play a vital role in the hyperparasitism process of Trichoderma on pathogens [36]. In addition, we also found that some Trichoderma strains had a distinctive coconut odor, which may be related to the production of the volatile compound namely 6-pentyl- $2 \mathrm{H}$ pyran-2-one (6PP) [37]. Wonglom et al. reported that $T$. asperellum $\mathrm{T} 1$ could produce 22 volatile compounds including $6 \mathrm{PP}$, which could inhibit the growth of two leaf spot fungal pathogens, Corynespora cassiicola and Curvularia aeria [38].

This study confirmed that 13 Trichoderma strains had a good growth-promoting effect on many crops. Trichoderma promotes plant growth by enhancing nutrient absorption efficiency and the secretion of growth-promoting metabolites in host plant [39]. Previous studies have shown that T. virens promotes the growth of Arabidopsis thaliana by mediating the activation of the classical auxin response pathway [40]. Additionally, diverse VOCs from T. asperellum also contribute immensely to plant growth $[37,38]$. Trichoderma T-22 could increase the efficiency of nitrogen application in maize, and under the same growth conditions, it could reduce the nitrogen application rate of corn by $40 \%$ [41]. Besides, Trichoderma can also induce plant hormone synthesis to promote plant growth by upregulating plant genes for hormone biosynthesis or downregulating hormone catabolism-related genes [42]. For instance, some reports suggested an indirect altered balance of the auxin hormone and cytokinin by Trichoderma, through the synthesis induction of these hormones by the plant, thereby achieving the purpose of promoting plant growth $[43,44]$.

As a mycorrhizal fungus, Trichoderma can successfully colonize in soil and plant roots, which is the premise of acting its biocontrol effect (including competition, growth promotion, antagonism, induced resistance) [45]. Trichoderma is precisely regulated in the process of colonizing plant roots. To successfully colonize roots, Trichoderma can instantly reduce the activity of root defense-system and promote its colonization in the root cortex [46]. Some reports suggested that root colonization by Trichoderma strains could increase levels of defense-related plant enzymes, including various peroxidases, chitinases, $\beta$ 1,3-glucanases, and the lipoxygenase-hydroperoxide lyase pathway $[47,48]$. In cucumber, root colonization by strain T-203 causes an increase in phenolic glucoside levels in leaves; their aglycones (which are phenolic glucosides with the carbohydrate moieties removed) are strongly inhibitory to a range of bacteria and fungi. Root colonization by these fungi therefore induces significant changes in the plant metabolic machinery [19]. In this study, we also evaluated the colonization ability of 13 Trichoderma strains on cucumber and found that all of them could colonize in the rhizosphere soil of cucumber, and the corresponding Trichoderma strain could also be isolated from other parts of cucumber, proving that they have strong colonization ability. However, the biocontrol effect of Trichoderma is the result of multiple mechanisms, and the interaction mechanism between Trichoderma, host plants, and pathogens needs to be further explored. 


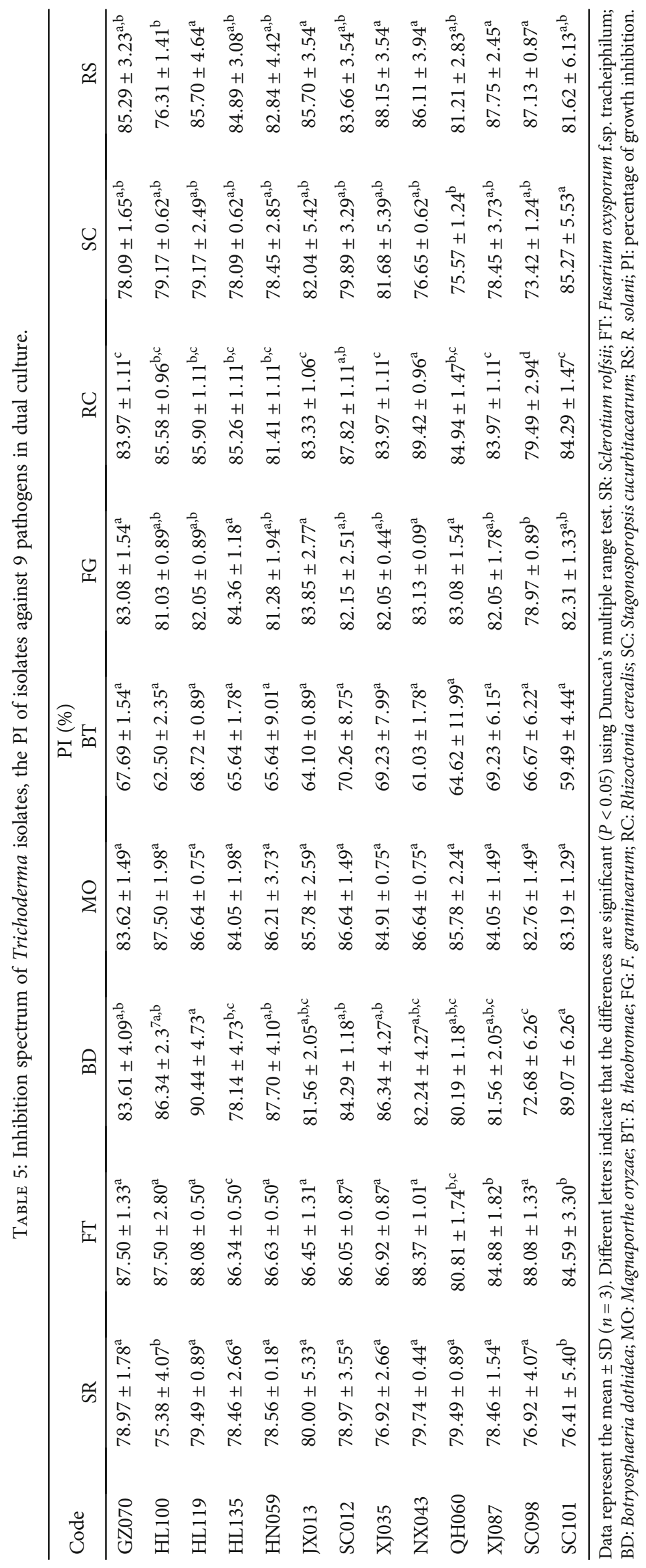




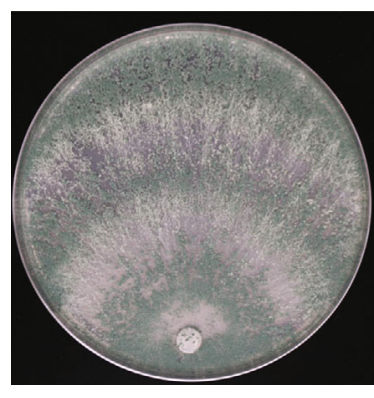

(a)

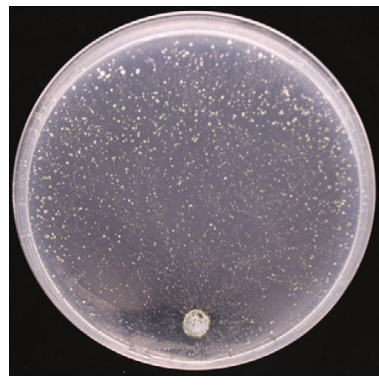

(c)

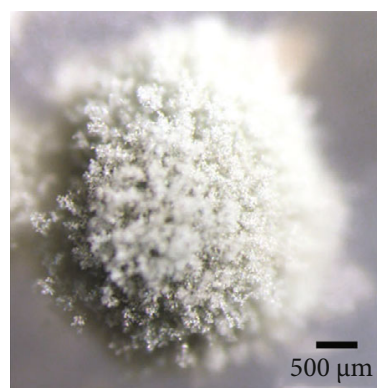

(e)

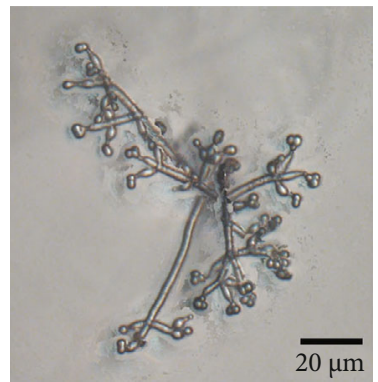

(g)

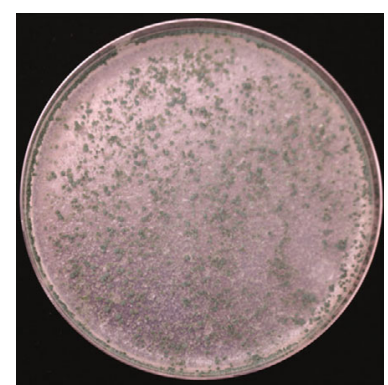

(b)

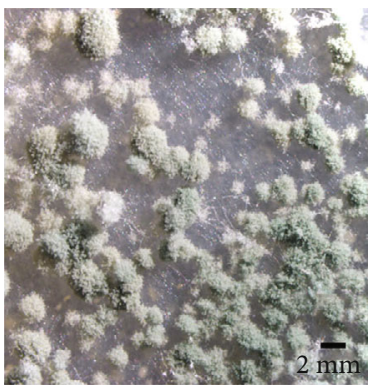

(d)

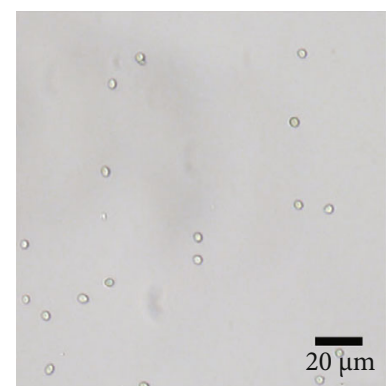

(f)

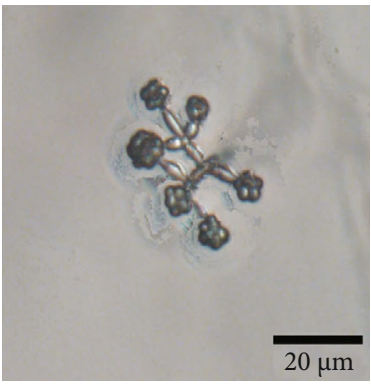

(h)

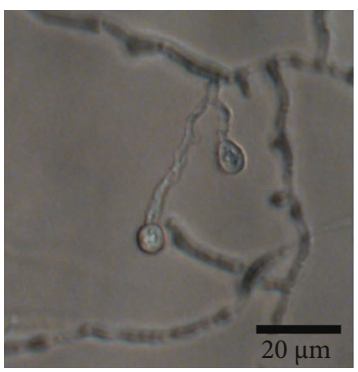

(i)

FIgURE 2: Morphological identification of JX013 (Trichoderma asperellum). (a-c) Cultures of JX013 that were grown on PDA, CMD, and SNA medium. (d, e) Conidial pustules. (f) Conidia. (g, h) Conidiophore. (i) Chlamydospores. PDA: potato dextrose agar medium; CMD: corn meal dextrose agar medium; SNA: synthetic low nutrient agar medium. 


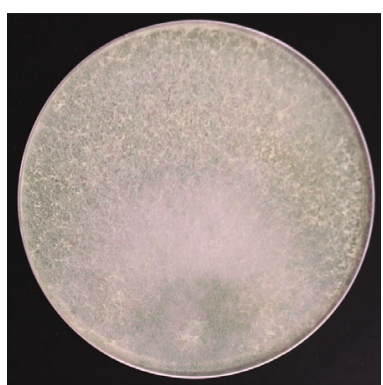

(a)

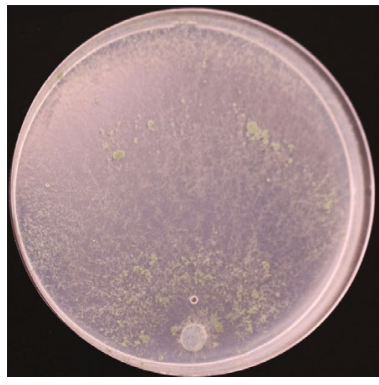

(c)

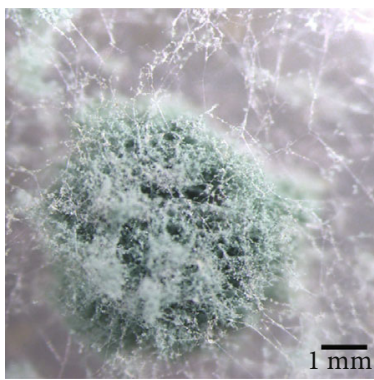

(e)

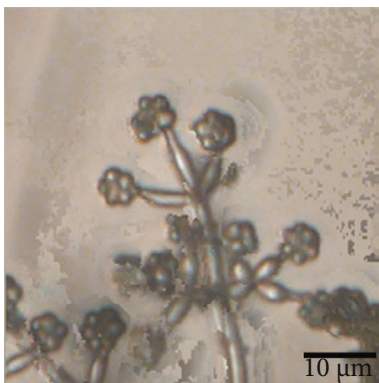

(g)

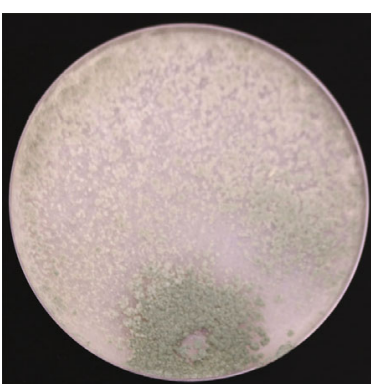

(b)

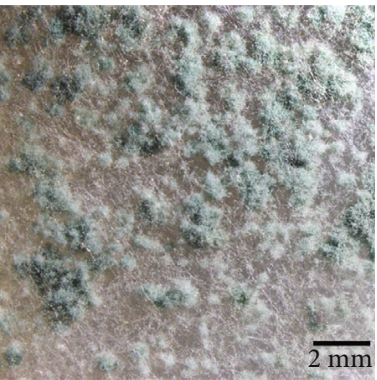

(d)

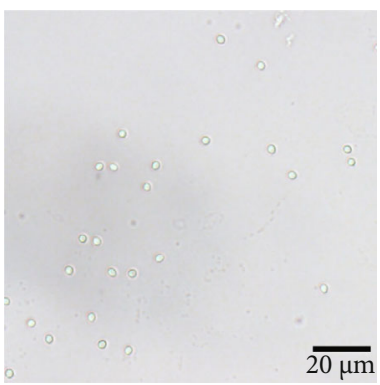

(f)

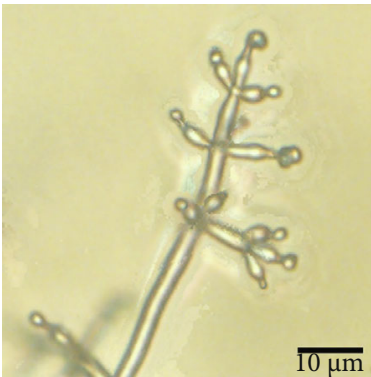

(h)

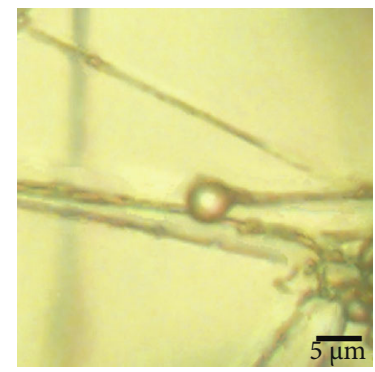

(i)

FIgURE 3: Morphological identification of SC098 (Trichoderma afroharzianum). (a-c) Cultures of JX013 which grew on PDA, CMD, and SNA medium. (d, e) Conidial pustules. (f) Conidia. (g, h) Conidiophore. (i) Chlamydospore. PDA: potato dextrose agar medium; CMD: corn meal dextrose agar medium; SNA: synthetic low nutrient agar medium. 

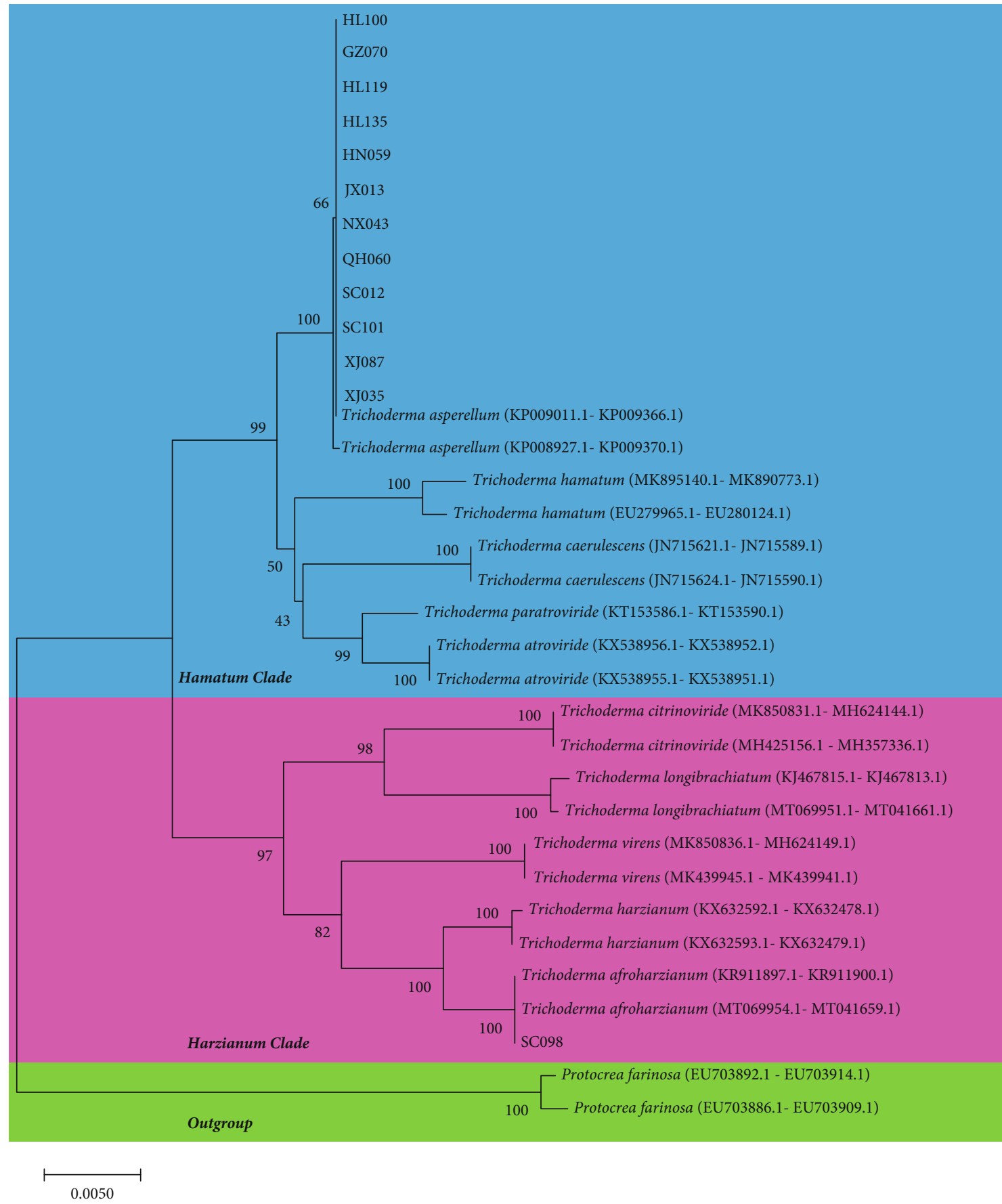

FIGURE 4: Phylogenetic analysis based on the tef- 1 gene and ITS region from the strains screened. GenBank accession numbers of 13 Trichoderma strains shown in Supplementary Table 2.

\section{Conclusion}

In this study, thirteen Trichoderma strains that showed high antagonistic potential against B. cinerea, F. oxysporum, and C. gloeosporioides were screened. At the same time, they could increase the germination rate of a variety of crop seeds, promote root growth, efficiently colonize in cucumber root soil, and show high $\beta$-1,3-glucanase and chitinase activities. These 13 strains of Trichoderma were identified as $T$. asperellum (12 strains) and T. afroharzianum (1 strain). These strains have good biological control potential, which provides a feasibility basis for the next evaluation of their field control effects and their application in production.

\section{Data Availability}

Data are available on request. 


\section{Conflicts of Interest}

The authors declare that they have no conflict of interest.

\section{Authors' Contributions}

Ming Xue and Rui Wang are the co first authors of this article. Ming Xue and Rui Wang contributed equally to this work.

\section{Acknowledgments}

This work was supported by the Scientific Research Projects of the Education Department of Hainan Province (Hnky2019ZD-4) and Scientific Research Project of Academician Innovation Platform of Hainan Province (YSPTZX202018).

\section{Supplementary Materials}

Supplementary Table 1 shows the types, cultivar, and sources of plant seeds or seedlings used in the study. Supplementary Table 2 shows the GenBank accession numbers of 13 Trichoderma strains. (Supplementary Materials)

\section{References}

[1] T. Benítez, A. M. Rincón, M. C. Limón, and C. C. Antonio, "Biocontrol mechanisms of Trichoderma strains," International Microbiology, vol. 8, pp. 249-260, 2004.

[2] L. H. Chen, X. Q. Huang, X. M. Yang, and Q. R. Shen, "Modeling the effects of environmental factors on the population offusarium oxysporumin cucumber continuously cropped soil," Communications in Soil Science \& Plant Analysis, vol. 44, no. 15, pp. 2219-2232, 2013.

[3] H. Halpern, M. T. Brewer, and R. C. Kemerait, "Genetic diversity and virulence of Fusarium oxysporum f. sp vasinfectum (FOV) races causing Fusarium wilt of cotton in the southeastern United States," Phytopathology, vol. 108, pp. 91-91, 2018.

[4] A. Uysal and S. Kurt, "Colletotrichum gloeosporiodes causing anthracnose on pomegranate in Turkey," Australasian Plant Disease, vol. 13, no. 1, p. 19, 2018.

[5] A. Imtiaj, S. A. Rahman, S. Alam et al., "Effect of fungicides and plant extracts on the conidial germination of Colletotrichum gloeosporioides causing mango anthracnose," Mycobiology, vol. 33, no. 4, pp. 200-205, 2005.

[6] J.-O. Kim, J.-H. Shin, A. Gumilang, K. Chung, K. Y. Choi, and K. S. Kim, "Effectiveness of different classes of fungicides on Botrytis cinerea causing gray mold on fruit and vegetables," The Plant Pathology Journal, vol. 32, no. 6, pp. 570-574, 2016.

[7] P. Leroux, M. Gredt, M. Leroch, and A. S. Walker, "Exploring mechanisms of resistance to respiratory inhibitors in field strains of Botrytis cinerea, the causal agent of gray mold," Applied and Environmental Microbiology, vol. 76, no. 19, pp. 6615-6630, 2010.

[8] F. J. López-Escudero and J. Mercado-Blanco, "Verticillium wilt of olive: a case study to implement an integrated strategy to control a soil-borne pathogen," Plant and Soil, vol. 344, no. 1-2, pp. 1-50, 2011.

[9] A. Kalia and S. K. Gosal, "Effect of pesticide application on soil microorganisms," Archives of Agronomy and Soil Science, vol. 57, no. 6, pp. 569-596, 2011.
[10] D. Haas and G. Défago, "Biological control of soil-borne pathogens by fluorescent pseudomonads," Nature Reviews Microbiology, vol. 3, no. 4, pp. 307-319, 2005.

[11] C. Keswani, S. P. Singh, and H. Singh, "A superstar in biocontrol enterprise: Trichoderma spp,” Biotech Today, vol. 3, no. 2, pp. 27-30, 2013.

[12] J. W. Kloepper, C. M. Ryu, and S. Zhang, "Induced systemic resistance and promotion of plant growth byBacillusspp," Phytopathology, vol. 94, no. 11, pp. 1259-1266, 2004.

[13] T. Matsuzawa and K. Yaoi, "Screening, identification, and characterization of a novel saccharide-stimulated $\beta$-glycosidase from a soil metagenomic library," Applied Microbiology and Biotechnology, vol. 101, no. 2, pp. 633-646, 2017.

[14] M. Schmoll, C. Dattenböck, N. Carreras-Villaseñor, A. Mendoza-Mendoza, and A. Herrera-Estrella, "The genomes of three uneven siblings: footprints of the lifestyles of three Trichoderma species," Microbiology and Molecular Biology Review, vol. 80, no. 1, pp. 205-327, 2016.

[15] J.-L. Chen, S.-Z. Sun, C.-P. Miao et al., "Endophytic_Trichoderma gamsii_ YIM PH30019: a promising biocontrol agent with hyperosmolar, mycoparasitism, and antagonistic activities of induced volatile organic compounds on root-rot pathogenic fungi of _Panax notoginseng_," Journal of Ginseng Research, vol. 40, no. 4, pp. 315-324, 2016.

[16] K. Saravanakumar, C. Yu, K. Dou, M. Wang, Y. Li, and J. Chen, "Synergistic effect of_Trichoderma_-derived antifungal metabolites and cell wall degrading enzymes on enhanced biocontrol of _Fusarium oxysporum_f. sp. _cucumerinum ," Biological Control, vol. 94, pp. 37-46, 2016.

[17] S. Halifu, X. Deng, X. Song, R. Song, and X. Liang, "Inhibitory mechanism of Trichoderma virens ZT05 on Rhizoctonia solani," Plants, vol. 9, no. 7, 2020.

[18] B. A. Maroua, D. Lopez, M. A. Triki, and K. Ali, "Beneficial effect of_Trichoderma harzianum_strain _Ths97_in biocontrolling _Fusarium solani_causal agent of root rot disease in olive trees," Biological Control, vol. 110, pp. 70-78, 2017.

[19] V. Nagy, V. Seidl, G. Szakacs, M. Komoń-Zelazowska, C. P. Kubicek, and I. S. Druzhinina, "Application of DNA bar codes for screening of industrially important fungi: the haplotype of Trichoderma harzianum sensu stricto indicates superior chitinase formation," Applied and Environmental Microbiology, vol. 73, no. 21, pp. 7048-7058, 2007.

[20] M. Verma, S. Brar, R. Tyagi, R. Surampalli, and J. Valero, "Antagonistic fungi,_Trichoderma_spp.: panoply of biological control," Biochemical Engineering Journal, vol. 37, no. 1, pp. 1-20, 2007.

[21] A. S. Kapoor, "Biocontrol potential of Trichoderma spp. against important soilborne diseases of vegetable crops," Indian Phytopathology, vol. 61, pp. 492-498, 2012.

[22] K. Perveen and N. A. Bokhair, "Antagonistic activity of Trichoderma harzianum and Trichoderma viride isolated from soil of date palm field against Fusarium oxysporum," Afircan Journal of Microbiology Researh, vol. 6, no. 13, pp. 33483353, 2012.

[23] F. Vinale, K. Sivasithamparam, E. L. Ghisalberti, R. Marra, S. L. Woo, and M. Lorito, “_Trichoderma_-plant-pathogen interactions," Soil Biology Biochemical, vol. 40, no. 1, pp. 1-10, 2008.

[24] S. Massart and H. M. Jijakli, "Use of molecular techniques to elucidate the mechanisms of action of fungal biocontrol agents: a review," Journal of Microbiological Methods, vol. 69, no. 2, pp. 229-241, 2007. 
[25] Y. Elad and I. Chet, "Improved selective media for isolation of Trichoderma spp. or Fusarium spp," Phytoparasitica, vol. 11, no. 1, pp. 55-58, 1983.

[26] M. C. O'Gorman, H. T. Fuller, and P. S. Dyer, "Discovery of a sexual cycle in the opportunistic fungal pathogen_Aspergillus fumigatus_," Nature, vol. 457, no. 7228, pp. 471-474, 2009.

[27] M. Mitsuboshi, Y. Kioka, K. Noguchi, and S. Asakawa, "An evaluation method for the suppression of pathogenic Fusarium oxysporum by soil microorganisms using the dilution plate technique," Microbes \& Environments, vol. 31, no. 3, pp. 307-313, 2016.

[28] G. L. Miller, "Use of dinitrosalicylic acid reagent for determination of reducing sugar," Analytical Chemistry, vol. 31, no. 3, pp. 426-428, 1959.

[29] W. K. Roberts and C. P. Selitrennikoff, "Plant and bacterial chitinases differ in antifungal activity," Microbiology, vol. 134, no. 1, pp. 169-176, 1988.

[30] W. Gams and J. Bissett, "Morphology and identification of Trichoderma," Trichoderma and Gliocladium, vol. 1, pp. 3-34, 1998.

[31] K. Ihrmark, N. Asmail, W. Ubhayasekera, P. Melin, J. Stenlid, and M. Karlsson, "Comparative molecular evolution of Trichoderma chitinases in response to mycoparasitic interactions," Evolutionary Bioinformatics, vol. 6, no. 6, p. EBO.S4198, 2010.

[32] K. Katoh and D. M. Standley, "MAFFT multiple sequence alignment software version 7: improvements in performance and usability," Molecular Biology and Evolution, vol. 30, no. 4, pp. 772-780, 2013.

[33] N. Manzar, Y. Singh, A. S. Kashyap et al., "Biocontrol potential of native _Trichoderma_spp. against anthracnose of great millet (_Sorghum bicolour__L) from Tarai and hill regions of India," Biological Control, vol. 152, p. 104474, 2021.

[34] T. I. Olabiyi and M. Ruocco, "In-vitro competition bio-assay experiment on the effect of Trichoderma species and some crop pathogenic fungi," Biology Agriculture Healthcare, vol. 3 , no. 12, 2013.

[35] F. B. Almeida, F. M. Cerqueira, R. N. Silva, and C. J. Ulhoa, "Mycoparasitism studies of Trichoderma harzianum strains against Rhizoctonia solani: evaluation of coiling and hydrolytic enzyme production," Biotechnology Letters, vol. 29, no. 8, pp. 1189-1193, 2007.

[36] A. Viterbo, M. Harel, and I. Chet, "Isolation of two aspartyl proteases from Trichoderma asperellum expressed during colonization of cucumber roots," FEMS Microbiology Letters, vol. 238, no. 1, pp. 151-158, 2004.

[37] N. Phoka, N. Suwannarach, S. Lumyong et al., "Role of volatiles from the endophytic fungus Trichoderma asperelloides PSU-P1 in biocontrol potential and in promoting the plant growth of Arabidopsis thaliana," Journal of Fungi, vol. 6, no. 4, p. 341, 2020.

[38] P. Wonglom, S. Ito, and A. Sunpapao, "Volatile organic compounds emitted from endophytic fungus _Trichoderma asperellum_ T1 mediate antifungal activity, defense response and promote plant growth in lettuce (_Lactuca sativa_)," Fungal Ecology, vol. 43, p. 100867, 2020.

[39] A. Martínez-Medina, M. D. M. Alguacil, J. A. Pascual, and S. C. M. Van Wees, "Phytohormone profiles induced by Trichoderma isolates correspond with their biocontrol and plant growth-promoting activity on melon plants," Journal of Chemical Ecology, vol. 40, no. 7, pp. 804-815, 2014.
[40] H. A. Contreras-Cornejo, L. Macías-Rodríguez, C. CortésPenagos, and J. LópezBucio, "Trichoderma virens, a plant beneficial fungus, enhances biomass production and promotes lateral root growth through an auxin-dependent mechanism in Arabidopsis," Plant Physiology, vol. 149, no. 3, pp. 15791592, 2009.

[41] G. E. Harman, "Myths and dogmas of biocontrol changes in perceptions derived from research onTrichoderma harzinumT-22," Plant Disease, vol. 84, no. 4, pp. 377-393, 2000.

[42] A. Sofo, G. Tataranni, C. Xiloyannis, B. Dichio, and A. Scopa, "Direct effects of _Trichoderma harzianum_strain T-22 on micropropagated shoots of GiSeLa6 ${ }^{\circledR}$ (_Prunus cerasus_ $\times$ _Prunus canescens_) rootstock," Enviromental and Experimental Botany, vol. 76, pp. 33-38, 2012.

[43] A. Sofo, A. Scopa, M. Manfra et al., "Trichoderma harzianum strain T-22 induces changes in phytohormone levels in cherry rootstocks (Prunus cerasus $\times$ P. canescens)," Journal of Plant Growth Regulation, vol. 65, no. 2, pp. 421-425, 2011.

[44] A. Martínez-Medina, A. Roldán, A. Albacete, and J. A. Pascual, "The interaction with arbuscular mycorrhizal fungi or _Trichoderma harzianum _ alters the shoot hormonal profile in melon plants," Phytochemistry, vol. 72, no. 2-3, pp. 223-229, 2011.

[45] A. Viterbo, U. Landau, S. Kim, L. Chernin, and I. Chet, "Characterization of ACC deaminase from the biocontrol and plant growth-promoting agent Trichoderma asperellum T203," FEMS Microbiology Letters, vol. 305, no. 1, pp. 42-48, 2010.

[46] J. Chen, "Advances on Trichoderma-induced plant resistance against diseases," Chinese Journal of Biological Control, vol. 31, pp. 733-741, 2015.

[47] C. R. Howell, L. E. Hanson, R. D. Stipanovic, and L. S. Puckhaber, "Induction of terpenoid synthesis in cotton roots and control ofRhizoctonia solaniby seed treatment withTrichoderma virens," Phytopathology, vol. 90, no. 3, pp. 248-252, 2000.

[48] I. Yedidia, M. Shoresh, Z. Kerem, N. Benhamou, Y. Kapulnik, and I. Chet, "Concomitant induction of systemic resistance to Pseudomonas syringae pv. lachrymansin cucumber by Trichoderma asperellum(T-203) and accumulation of phytoalexins," Applied and Environmental Microbiology, vol. 69, no. 12, pp. 7343-7353, 2003. 